\title{
Thermal Evaluation, Rheological Properties and Characterization of Pristine, Modified and Polyacrylamide-Mediated Grafted Acacia modesta Gum
}

\author{
Hira Munir ${ }^{1}$, Muhammad Shahid ${ }^{2}$, Muhammad Bilal ${ }^{3 *}$ (D) and \\ Hafiz M.N. Iqbal ${ }^{4 *}$ (D) \\ ${ }^{1}$ Department of Biochemistry and Biotechnology, University of Gujrat, Gujrat, Pakistan. ${ }^{2}$ Department \\ of Biochemistry, University of Agriculture, Faisalabad, Pakistan. ${ }^{3}$ School of Life Science and Food \\ Engineering, Huaiyin Institute of Technology, Huaian 223003, China. ${ }^{4}$ Tecnologico de Monterrey, School of \\ Engineering and Sciences, Campus Monterre, Ave. Eugenio Garza Sada 2501, CP 64849 Monterrey, Mexico.
}

\begin{abstract}
Naturally occurring plant-based gums are being widely used in different industries due to their unique thickening and gelling potentialities. The research was planned to evaluate the influence of hydrolysis and modification on rheological and thermal properties of Acacia modesta (Phulai) gum extracts. The gum was hydrolyzed and modified by different chemical methods including polyacrylamide grafting, carboxymethylation, acidic and basic hydrolysis to alter the viscosity behavior. The rheological behavior of selected gum extracts was studied. The change in structure and thermal behavior after processing was determined by Differential scanning calorimetry (DSC), X-ray diffraction (XRD), Thermogravimetric analysis (TGA) and Fourier transforms infrared spectroscopy (FTIR). The analysis of DSC and TGA revealed that the processed gum samples were thermally more stable as compared to pristine counterpart of the crude gum. The present results of $A$. modesta would be useful for incorporation in various applications in the food and pharmaceutical industries.
\end{abstract}

Keywords: Natural gum, grafting, polyacrylamide, carboxymethylation, characterization

*Correspondence: bilaluaf@hotmail.com (M. Bilal); hafiz.iqbal@tec.mx (H.M.N. Iqbal).

(Received: April 09, 2020; accepted: April 24, 2020)

Citation: Munir H, Shahid M, Bilal M, Iqbal HMN. Thermal Evaluation, Rheological Properties and Characterization of Pristine, Modified and Polyacrylamide-Mediated Grafted Acacia modesta Gum. J Pure Appl Microbiol. 2020;14(2):1397-1403. doi: 10.22207/JPAM.14.2.37

(C) The Author(s) 2020. Open Access. This article is distributed under the terms of the Creative Commons Attribution 4.0 International License which permits unrestricted use, sharing, distribution, and reproduction in any medium, provided you give appropriate credit to the original author(s) and the source, provide a link to the Creative Commons license, and indicate if changes were made. 


\section{INTRODUCTION}

Throughout the ages, natural products are being used by humans for their basic necessities as food, medicines, shelter and clothing. Plants have provided medicines for the cure of various diseases such as leukemia, malaria, parasitic infection, diabetes, cardiovascular and respiratory disorders ${ }^{1,2}$. Nowadays, research of medicinal plants has been the center of attraction due to their potential be used for various applications in pharmaceutical industry. All over the world research of medicinal plants has been increased ${ }^{3,4}$.

Carbohydrate consists of dry weight (<90\%) and carbohydrate polymers are known as polysaccharides ${ }^{5,6}$. The basic source of carbohydrate molecules are natural polymers ${ }^{7,8}$. Because of their biosafety and sustainability, carbohydrate polymers have been the subject of contemporary research ${ }^{9}$. Polymers extracted from natural sources are comparatively non-toxic and cheap ${ }^{8,9}$.

Natural gums are polysaccharides with heterogenous composition that consist of many sugars like glucose, mannose, galactose, arabinose, rhamnose, xylose and uronic acids. These gums are well known in formation of three dimensional interconnected molecular networks termed as gels. The potency of these gels depends on the concentration and structure of the gum, along with factor like $\mathrm{pH}$, temperature and ionic strength. Many of the gums are safe for consumption and are being used as food additives and in drug delivery. Chemical modification improves the capability of gums for their use in different fields like drug delivery ${ }^{10}$.

Native, unmodified and crude gums exhibits few drawbacks of their use for different applications such as lack of clarity, free-flowing properties, uncontrol rate of hydration and thickening, on storage a decrease in viscosity, microbial contamination and formation of bigger microstructure that can be overcomed by modifying the physicochemical properties by using different modification methods $s^{9-12}$.

Acacia modetsa belongs to Fabaceae family is commonly known as phulai. It is widely distributed in Pakistan, India, and Afghanistan. Its wood is hard and durable and is used in the preparation of Persian wheels, agricultural implements, and cane crushers. It can also be used as a fuel ${ }^{1}$. Structure of Acacia modesta consist of angular fragments. It is a translucent and yellow color gum ${ }^{13}$. It is used for the treatment of wounds, leprosy, venereal diseases and dysentery, whereas its ash is helpful for relief of severe body pain. The mixture of its gum along with almond, butter, and wheat flour is also given to women after delivery ${ }^{1}$. Gum acacia is a complex polysaccharide exudate, that is obtained from the trees of Acacia species, this exudate protects the tree against the external attacks $^{14}$. Antimicrobial potential of extracts of leaves and stem has also been estimated that leads to use of young twigs of this plant as tooth stick (miswak) ${ }^{15,16}$. Hepatoprotective potential of $A$. modesta (Bark extract) has also been reported in plasma proteins level and serum levels of hepatic metabolic enzymes were used for the analysis of hepatotoxicity ${ }^{17}$. Zhuble sharbat, a solution of gum, was taken as health stimulant. Plant use was also seen in the treatment of cough ${ }^{1}$. There is a lot of information, data, and literature, but very limited work reported in the present direction until now. Accordingly, this research was designed to determine the influence of modification on thermal and rheological behavior of different gum extracts of Acacia modesta.

\section{MATERIALS AND METHODS \\ Collection and purification of Acacia modesta}

The gum was procured from a local market in Faisalabad, Pakistan. The crude gum was purified using a method earlier described by Shahid et al. ${ }^{18}$, dried gum (as that the crude gum) was dissolved in dist. water at room temperature. This gum solution was then left to swell for the formation of a viscous solution. The solution was continuously stirred at room temperature for $6 \mathrm{~h}$ and then was filtered. Ethanol was added to the solution to obtain white amorphous precipitates. The precipitates were filtered and once washed with ethanol. The collected precipitated were dried in a hot air oven at $40^{\circ} \mathrm{C}$, after drying the gum was ground to a fine powder and was stored as the purified gum.

\section{Elemental analysis, modification and hydrolysis} of $A$. modesta gum

The elemental composition of the $A$. modesta gum was determined by Laser-induced breakdown spectroscopy (LIBS). Acacia modesta was chemically modified and hydrolyzed to alter 
its properties by the following methods:

\section{Modification of $A$. modesta gum}

For modification of gum two chemical methods were used. For polyacrylamide grafting a method described by Singh et al. ${ }^{19}$ was performed. To gum solution acrylamide, silver nitrate and ascorbic acid were added. This solution was kept at $35^{\circ} \mathrm{C}$, after $30 \mathrm{~min}, \mathrm{~K}_{2} \mathrm{~S}_{2} \mathrm{O}_{8}$ was added and solution was left for $1 \mathrm{~h}$ for reaction. Polyacrylamide grafted gum was separated from the solution by precipitation using ethanol. The collected modified gum was dried at 50 ㅇ. In a second method the gum was modified through carboxymethylation ${ }^{20}$. At room temperature, $\mathrm{NaOH}(10 \mathrm{~mL})$ was added to gum solution within $15 \mathrm{~min}$ at rate of $1 \mathrm{~mL}$ with continuous stirring. To this reaction mixture, $15 \mathrm{~mL}$ of chloroacetic acid was added. The carboxymethylated gum was extracted through precipitation technique using ethanol and was dried in oven for further use.

\section{Hydrolysis of $A$. modesta gum}

Acidic, basic and enzymatic hydrolysis of purified $A$. modesta sample was performed. For acidic hydrolysis, $0.2 \mathrm{mg}$ of purified gum was added to trifluoroacetic acid (2 M) and kept for $2 \mathrm{~h}$ at $110{ }^{\circ} \mathrm{C}$. The acidic hydrolyzed gum sample was precipitated and was oven dried ${ }^{21}$. A method described by Beltran ${ }^{22}$ was used for the basic hydrolysis. In $200 \mathrm{~mL}$ of barium hydroxide solution $5 \mathrm{~g}$ of gum was dissolved, followed by the addition of $\mathrm{H}_{2} \mathrm{SO}_{4}(1 \mathrm{M})$ to neutralize the solution. Using absolute ethanol, the hydrolyzed sample was precipitated and collected. The hydrolyzed gum was filtered and dried at $50 \stackrel{\circ}{\circ}$.

\section{Rheological analysis (Flow test)}

Flow test gives information about the viscous nature of a sample by the help of steady state flow (23). It was carried out to study the flow behavior of different samples of $A$. modesta.

\section{Characterization of Acacia modesta}

To study the possible functional groups and chemistry of gum in different forms Fourier transform infrared spectra were recorded within the range $500 \mathrm{~cm}^{-1}$ to $4000 \mathrm{~cm}^{-124}$. The changes in thermal behavior of gum samples after different treatments such as hydrolysis and modification were determined through thermogravimetric analyzer ${ }^{25}$. Differential scanning calorimetry was performed to determine the quantity of energy absorbed or released by the gum sample when it was heated. X-ray crystallography was used to determine the amorphous or crystalline nature of gum samples through an X-ray diffractometer ${ }^{24}$.

\section{RESULTS AND DISCUSSION}

Crude gum of $A$. modesta was modified and hydrolyzed by different methods. The effect of hydrolysis and modification was studied by different techniques.

\section{Elemental and rheological analysis (Flow test) of}

\section{A. modesta gum}

For the elemental (micro and macro)

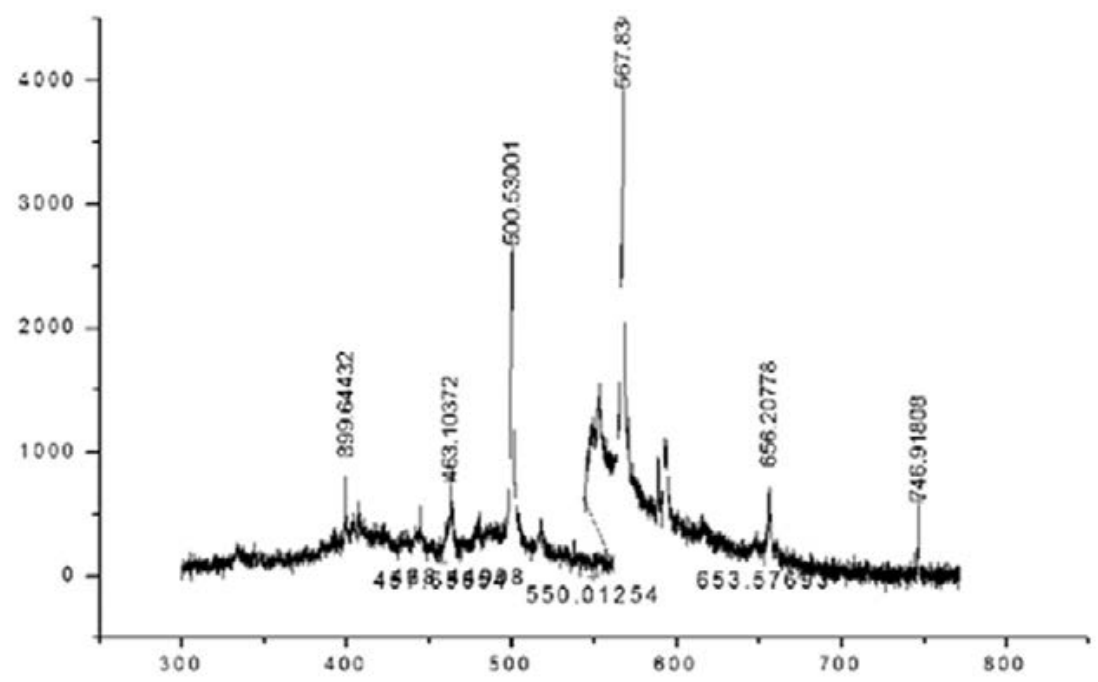

Fig. 1. Laser Induced Breakdown Spectroscopy (LIBS) spectra of crude A. modesta. 
analysis, LIBS was carried out. It is an analytical technique used to determine elemental composition of a sample. The spectrum of crude A. modesta obtained from LIBS is presented in Fig 1. It was carried out to investigate about the alteration in the viscous nature of gum samples after the process of different treatments. The test was performed using rheometer. Viscosity $(\mathrm{Pa})$ was plotted against shear rate $\left(\mathrm{s}^{-1}\right)$ (Fig. 2). Test reveals that there was a drop in the viscosity after the modification and hydrolysis. The sequence of this test using $A$. modesta gum samples is given as follow:

Purified $>$ Crude $>$ Acidic hydrolysis $>$ Basic hydrolysis $>$ Polyacrylamide grafted > Carboxymethylation

\section{Analytical characterization}

Fourier transforms infrared (FTIR) spectroscopy

FTIR spectroscopy has been used extensively for the characterization of samples.

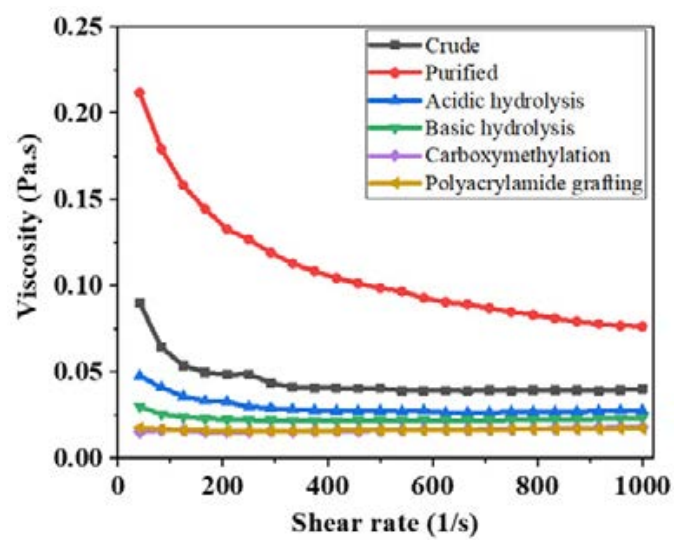

Fig. 2. Flow curves of $A$. modesta (Viscosity vs. shear rate)

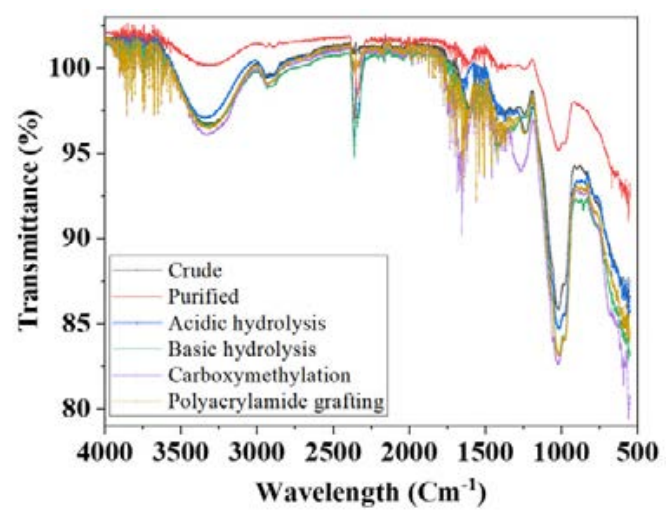

Fig. 3. Fourier transform infrared spectra of crude (a) purified (b) acidic hydrolysis (c) basic hydrolysis (d) polyacrylamide grafting (e) carboxymethylation (f)
It provides information related to molecular structure and functional groups. Through FTIR spectra, the vibrations in polymers that affect the intermolecular interactions can be determined. The recorded spectra of gum samples are presented in Fig 3, by studying \% transmittance and wavenumber $\left(\mathrm{cm}^{-1}\right)$. The FTIR spectra of all gums samples exhibits the $\mathrm{C}-\mathrm{C}$ stretching vibrations are between the range of 800 and $1200 \mathrm{~cm}^{-1}$, while the absorbance bands present within the range of $900-1200 \mathrm{~cm}^{-1}$, indicates the presence of C-O (anhydrides) stretching vibrations. Whereas, the peaks between 1500 and $1600 \mathrm{~cm}^{-1}$ corresponds to $\mathrm{C}=\mathrm{C}$ (alkenes) stretching vibrations. Hydroxyl group $(\mathrm{O}-\mathrm{H})$ is present in all gum samples that reveals the availability of hydrogen bonding ${ }^{26}$. The $(\mathrm{O}-\mathrm{H})$ group are the basis of complex carbohydrate structures as they provide strength due to intra and intermolecular bound hydroxyl groups ${ }^{27}$.

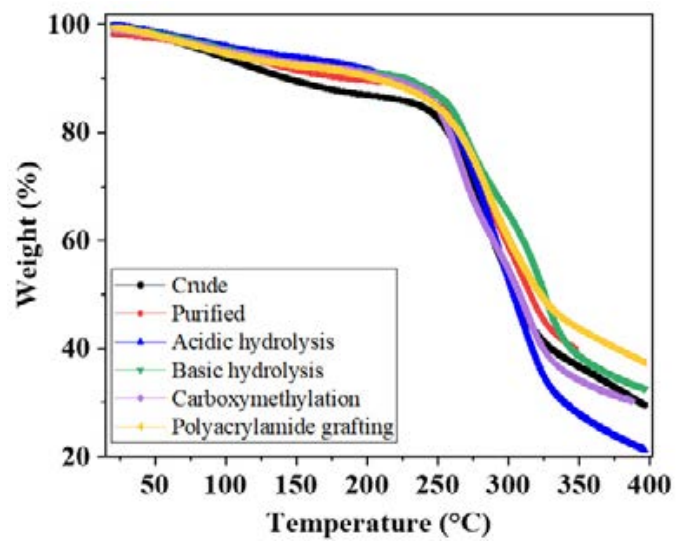

Fig. 4. Thermogravimetric analysis of $A$. modesta crude (a) purified (b) acidic hydrolysis (c) basic hydrolysis (d) polyacrylamide grafting (e) carboxymethylation ( $f$ )

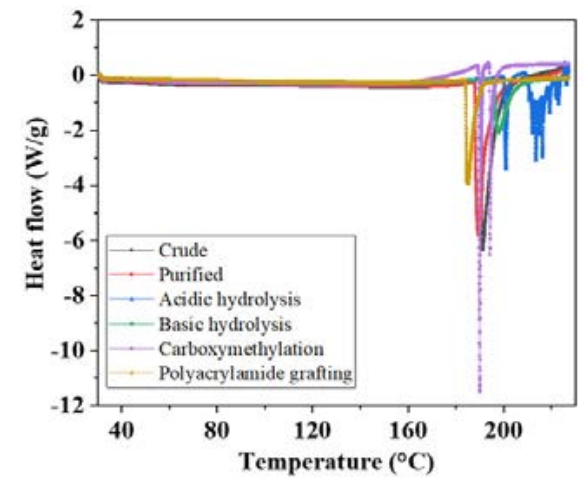

Fig. 5. Differential scanning calorimetry of $A$. modesta crude (a) purified (b) acidic hydrolysis (c) basic hydrolysis (d) polyacrylamide grafting (e) carboxymethylation (f) 


\section{Thermo-gravimetric analysis}

TGA is an advance technique used for the determination of thermal stability and decomposition pattern of polymers. The thermographs were taken to determine the weight loss occurred on heating the gum
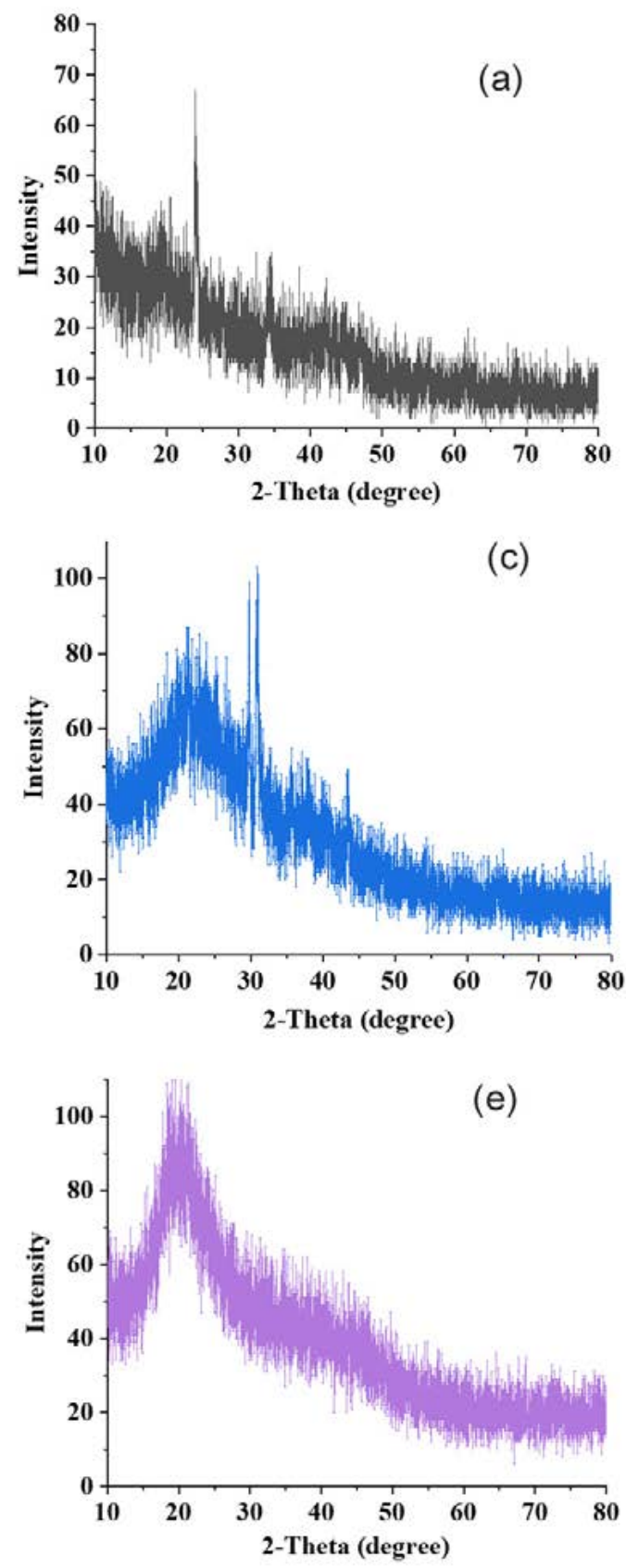

samples. Thermogravimetric analysis is the function of temperature and time ${ }^{18,26}$. In all gum samples of Acacia modesta, the first weight loss, which was minor is the loss of structural and adsorbed water of polymers. The second major weight loss is because of the decomposition of
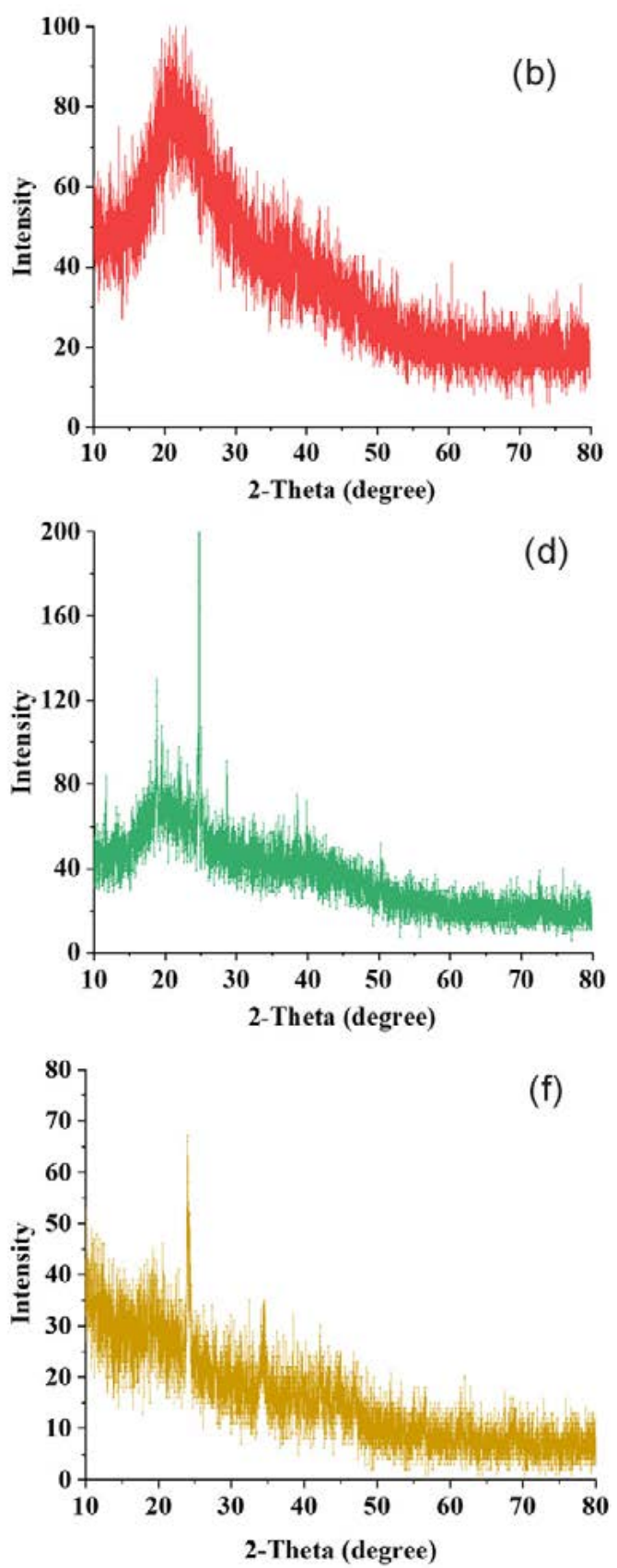

Fig. 6. X-ray diffraction (XRD) patterns of $A$. modesta crude (a) purified (b) acidic hydrolysis (c) basic hydrolysis (d) polyacrylamide grafting (e) carboxymethylation (f). 
polysaccharides6. The thermogravimetric spectra of $A$. modesta gum samples are presented in Fig 4. The decomposition of crude gum starts at 76 ${ }^{\circ} \mathrm{C}$. In the case of processed gum samples, this temperature was increased, indicating that these gum samples were thermally more stable than the crude gum samples. The major weight loss of all gum samples was seen in second stage of thermal decomposition.

\section{Differential scanning calorimetry}

DSC of samples was carried out to determine the exothermal and endothermal changes followed with the rise in temperature. Colorimetry is generally carried out to analyze the phase transitions taking place in polymers, because of their sensitivity and accuracy. Fig 5 represent the DSC of $A$. modesta samples. Different structural and functional group in plant gums affect the transition temperature thermal behavior (6). The glass transition temperature ( $\mathrm{Tg}$ ) of polymers is associated with the crystalline and amorphous behavior. A lower $\mathrm{Tg}$ indicates the lower degree of crystallinity with a high degree of amorphous nature. A higher degree of crystallinity gives the structural stability to polymers and make the granules more resistant towards high temperature. The determination of $\mathrm{Tg}$ is important for the storage and production processes. Moisture also have influence on the $\mathrm{Tg}$ (26).

\section{X-ray diffraction}

To determine the crystalline or amorphous structure of $A$. modesta gum the XRD pattern was recorded (Fig 6). The XRD pattern of hydrolyzed gum samples showed sharp peaks that reveals the crystallinity structure. The polyacrylamide grafted (modified) sample of exhibits a sharp diffraction peak that was a confirmation of the crystalline nature, indicating the successful polyacrylamide grafting. The carboxymethylated gum also showed a sharp peak, signifying the crystallinity. Overall, it can be concluded that after the modification and hydrolysis there was an increase in degree of crystallinity in $A$. modesta gum.

\section{CONCLUSION}

Different structural techniques including XRD, TGA, DSC, and FT-IR confirmed the modification and hydrolysis of $A$. modesta gum. The results of TGA and DSC reveals that there was an increase in thermal potential of processed gums. The XRD analysis also indicates an increase in crystalline nature of gums after the modification. An increase in crystallinity makes $A$. modesta gum more heat resistance. Though, there was a decrease in viscosity of gum solutions, studied by performing a flow test.

\section{ACKNOWLEDGMENTS}

Authors are highly thankful to Higher Education Commission (HEC), Government of Pakistan, Islamabad for providing the funds for this research work under indigenous and IRSIP (International research support initiative program) Ph.D. program. We are also acknowledging Prof. Dr. Duncan Craig and Dr. Susan Barker from the School of Pharmacy, University College London, UK for providing laboratory facilities in this research work.

\section{CONFLICT OF INTEREST}

The authors declare that there is no conflict of interest.

\section{AUTHORS' CONTRIBUTION}

All listed author(s) have made a substantial, direct and intellectual contribution to the work, and approved it for publication.

\section{FUNDING}

None.

\section{ETHICS STATEMENT}

This article does not contain any studies with human participants or animals performed by any of the authors.

\section{DATA AVAILABILITY}

Not applicable.

\section{REFERENCES}

1. Sarwar W. Pharmacological and phytochemical studies on Acacia modesta Wall.; A review. The Journal of Phytopharmacology. 2016;5(4):160-166.

2. Ishaq $N$, Bilal $M$, Iqbal H. Medicinal potentialities of plant defensins: a review with applied perspectives. Medicines. 2019;6(1):29. https://doi.org/10.3390/ medicines6010029

3. Suvakanta D, Narsimha MP, Pulak D, Joshabir C, Biswajit D. Optimization and characterization of purified polysaccharide from Musa sapientum L. as a pharmaceutical excipient. Food chemistry. 
2014;149:76-83. https://doi.org/10.1016/j. foodchem.2013.10.068

4. Hao DC, Xiao PG. Pharmaceutical resource discovery from traditional medicinal plants: Pharmacophylogeny and pharmacophylogenomics. Chinese Herbal Medicines. 2020. https://doi.org/10.1016/j. chmed.2020.03.002

5. Zohuriaan MJ, Shokrolahi F. Thermal studies on natural and modified gums. Polymer Testing. 2004;23(5):575-579. https://doi.org/10.1016/j. polymertesting.2003.11.001

6. Bothara SB, Singh S. Thermal studies on natural polysaccharide. Asian Pac J Trop Biomed. 2012;2(2):S1031-1035. https://doi.org/10.1016/ S2221-1691(12)60356-6

7. Cerqueira MA, Pinheiro AC, Souza BW, et al. Extraction, purification and characterization of galactomannans from non-traditional sources. Carbohydrate Polymers. 2009;75(3):408-414. https://doi.org/10.1016/j. carbpol.2008.07.036

8. Prajapati VD, Jani GK, Moradiya NG, Randeria NP. Pharmaceutical applications of various natural gums, mucilages and their modified forms. Carbohydrate Polymers. 2013;92(2):1685-1699. https://doi. org/10.1016/j.carbpol.2012.11.021

9. Rana V, Rai P, Tiwary AK, Singh RS, Kennedy JF, Knill CJ. Modified gums: Approaches and applications in drug delivery. Carbohydrate Polymers. 2011;83(3):10311047. https://doi.org/10.1016/j.carbpol.2010.09.010

10. George A, Shah PA, Shrivastav PS. Guar gum: Versatile natural polymer for drug delivery applications. Eur Polym J. 2019;112:722-735. https://doi.org/10.1016/j. eurpolymj.2018.10.042

11. Prabaharan M, Jayakumar R. Chitosan-graft- $\beta$ cyclodextrin scaffolds with controlled drug release capability for tissue engineering applications. Int J Biol Macromol. 2009;44(4):320-325. https://doi. org/10.1016/j.ijbiomac.2009.01.005

12. Kumar A, Ahuja M. Carboxymethyl gum kondagogu: synthesis, characterization and evaluation as mucoadhesive polymer. Carbohydrate Polymers. 2012;90(1):637-643. https://doi.org/10.1016/j. carbpol.2012.05.089

13. Nussonovitch A. Plant Gum Exudates of the World: Sources. Distribution, Properties and Application, 1st ed., CRC: Florida. 2010. https://doi. org/10.1201/9781420052244

14. Apolinar-Valiente R, Williams P, Nigen M, Tamayo VM, Doco T, Sanchez C. Fractionation of Acacia seyal gum by ion exchange chromatography. Food Hydrocolloids. 2020;98:105283. https://doi.org/10.1016/j. foodhyd.2019.105283

15. Napar AA, Bux H, Zia MA, et al. Antimicrobial and antioxidant activities of Mimosaceae plants; Acacia modesta Wall (Phulai), Prosopis cineraria (Linn.) and Prosopis juliflora (Swartz). I Med Plant Res. 2012;6(15):2962-2970. https://doi.org/10.5897/

\section{JMPR11.1349}

16. Khan N, Ahmad M, Khan RA, Khan ST, Muhammad N. Investigation of Acacia modesta leaves for in-vitro antioxidant activity, enzyme inhibition and cytotoxicity. World Appl Sci J. 2014;30(3):286-293.

17. Rahaman MS, Chaudhry MA. Evaluation of antioxidant and hepatoprotective effect of Acacia modesta wall against paracetamol induced hepatotoxicity. British Journal of Pharmaceutical Research. 2015;5(5):336343. https://doi.org/10.9734/BJPR/2015/15559

18. Shahid M, Bukhari SA, Gul Y, et al. Graft polymerization of guar gum with acryl amide irradiated by microwaves for colonic drug delivery. Int J Biol Macromol. 2013;62:172-179. https://doi.org/10.1016/j. ijbiomac.2013.08.018

19. Singh V, Srivastava A, Tiwari A. Structural elucidation, modification and characterization of seed gum from Cassia javahikai seeds: A non-traditional source of industrial gums. Int J Biol Macromol. 2009;45(3):293297. https://doi.org/10.1016/j.ijbiomac.2009.06.007

20. Dodi G, Hritcu D, Popa MI. Carboxymethylation of guar gum: synthesis and characterization. Cellulose chemistry and Technology. 2011;45(3):171.

21. Grobl M, Harrison S, Kaml I, Kenndler E. Characterisation of natural polysaccharides (plant gums) used as binding media for artistic and historic works by capillary zone electrophoresis. Journal of Chromatography A. $2005 ; 1077(1): 80-89$. https://doi.org/10.1016/j. chroma.2005.04.075

22. Beltran O, de Pinto GL, Rincon F, Picton L, Cozic C, Le Cerf D, Muller G. Acacia macracantha gum as a possible source of arabinogalactan-protein. Carbohydrate Polymers. 2008;72(1):88-94. https:// doi.org/10.1016/j.carbpol.2007.07.027

23. Rincon F, Munoz J, De Pinto GL, Alfaro MC, Calero $\mathrm{N}$. Rheological properties of Cedrela odorata gum exudate aqueous dispersions. Food Hydrocolloids. 2009;23(3):1031-1037. https://doi.org/10.1016/j. foodhyd.2008.08.006

24. Munir H, Shahid M, Anjum F, Mudgil D. Structural, thermal and rheological characterization of modified Dalbergia sissoo gum-A medicinal gum. Int $\mathrm{J}$ Biol Macromol. 2016;84:236-245. https://doi. org/10.1016/j.ijbiomac.2015.12.001

25. Nep El, Conway BR. Characterization of grewia gum, a potential pharmaceutical excipient. Journal of Excipients and Food Chemicals. 2010;1(1):30-40.

26. Emeje M, Isimi C, Byrn S, Fortunak J, Kunle O, Ofoefule S. Extraction and physicochemical characterization of a new polysaccharide obtained from the fresh fruits of Abelmoschus esculentus. IJPR. 2011;10(2):237.

27. Ullah AA, Munir H, Shahid M. Synthesis of Bombax malabaricum gum based silver and zinc nanoparticles and their application in controlled drug delivery. Materials Research Express. 2019;6(11):115414. https://doi.org/10.1088/2053-1591/ab5235 